\title{
EVASÃO E PERMANÊNCIA ESTUDANTIL NO INSTITUTO FEDERAL DE SÃO PAULO: REFLEXÕES
}

\section{ARTIGO ORIGINAL}

KIESSLING, Hélio Fritz ${ }^{1}$, CRUZ, Maria do Carmo Meirelles Toledo ${ }^{2}$, ALMEIDA, Júlio Gomes $^{3}$

KIESSLING, Hélio Fritz. CRUZ, Maria do Carmo Meirelles Toledo. ALMEIDA, Júlio Gomes. Evasão e permanência estudantil no instituto federal de São Paulo: reflexões. Revista Científica Multidisciplinar Núcleo do Conhecimento. Ano 06, Ed. 08, Vol. 04, pp. 171-193. Agosto de 2021. ISSN: 2448-0959, Link de acesso: https://www.nucleodoconhecimento.com.br/educacao/instituto-federal, DOI: 10.32749/nucleodoconhecimento.com.br/educacao/instituto-federal

\footnotetext{
${ }^{1}$ Mestrando em Educação pela Universidade Cidade de São Paulo (em curso). Especialista em Formação de Professores para o Nível Superior pelo Instituto Federal de São Paulo. Licenciatura em Eletrotécnica para o Ensino Médio Profissionalizante pela Universidade Federal de São Carlos. Graduado em Engenharia de Produção pela Faculdade de Engenharia Industrial. Graduado em Engenharia Elétrica de Operação pela Faculdade de Engenharia Industrial. Técnico em Eletrotécnica pela Escola Técnica Federal de São Paulo. ORCID: https://orcid.org/0000-0002-2897-0629

${ }^{2}$ Orientadora. Doutorado em Administração Pública e Governo pela Escola de Administração de Empresas de São Paulo da Fundação Getulio Vargas - EAESP-FGV . Mestrado em Administração Pública e Governo pela EAESP-FGV. Especialização em Administração para Organizações do Terceiro Setor pela EAESP-FGV. Graduação em Administração Pública pela EAESP-FGV. ORCID: https://orcid.org/00000003-4375-5270

${ }^{3}$ Doutorado em Educação pela Universidade de São Paulo - USP; Mestrado em Educação pela Universidade de São Paulo; Graduação em Pedagogia pela Universidade de Guarulhos; Graduação em Letras pela Pontifícia Universidade Católica de São Paulo. ORCID: https://orcid.org/0000-0002-90938785
}

$\mathrm{RC}: 94514$

Disponível em: https://www.nucleodoconhecimento.com.br/educacao/instituto-federal 


\section{RESUMO}

Neste artigo, aborda-se o tema da permanência estudantil e considera-se a igualdade de condições para o acesso e a permanência do aluno na escola como um dos princípios constitucionais para garantir o direito à Educação. Objetiva-se conhecer textos produzidos por autores que mantêm vínculos com o Instituto Federal de São Paulo (IFSP) e que abordam ações de permanência estudantil de alunos no Instituto como meio de reduzir a evasão. Na pesquisa bibliográfica exploratória, foram considerados trabalhos acadêmicos produzidos por servidores e discentes do IFSP cujos temas são evasão e permanência estudantil. A análise desses trabalhos envolveu o conteúdo dos resumos, as palavras-chaves e as considerações finais dos trabalhos por eles escritos. Assim, identificou-se que os autores veem a evasão como um fenômeno complexo que envolve fatores pessoais, sociais e institucionais. Nas produções analisadas, há um diálogo entre evasão e permanência e é apontada a necessidade da união de esforços para criar ações que, somadas às já existentes, contribuam para que os alunos permaneçam na escola e finalizem seus estudos. Destacam, ainda, a importância das ações da assistência estudantil promovidas pelo IFSP, assim como melhorias da qualidade da Educação por meio de ações que envolvam ambiente escolar, acesso, infraestrutura, currículo, gestão, profissionais da Educação e apoio didático-pedagógico.

Palavras-chave: Permanência Estudantil, Ensino Profissionalizante, Instituto Federal de São Paulo.

\section{INTRODUÇÃO}

Este trabalho foi elaborado a partir de experiências vivenciadas por um dos autores durante a atuação como docente na Escola Técnica Federal de São Paulo (ETFSP), no período de 1977 a 1996, e no Instituto Federal de Educação, Ciência e Tecnologia de São Paulo (IFSP), a partir de 2013, acumulando a função de coordenador do curso de Eletrotécnica, de 2016 a 2019. O referencial teórico resulta de pesquisa

RC: 94514

Disponível em: https://www.nucleodoconhecimento.com.br/educacao/instituto-federal 
documental exploratória que embasa a dissertação de mestrado "A Educação como Direito: A Permanência como Princípio na Educação Profissional Integrada ao Ensino Médio", que está em fase de desenvolvimento no Programa de Pós-graduação em Educação (PPGE) da Universidade Cidade de São Paulo (UNICID).

O propósito é refletir sobre o tema da permanência estudantil no IFSP. Na primeira seção, são apresentados dados divulgados pela Plataforma Nilo Peçanha (PNP)[4] e alguns recortes de trabalhos produzidos por Daros (2013); Antunes (2018); Silva e Haas (2019); Dore e Lüscher (2011); Lins (2021) e Cislaghi (2008), com enfoque em evasão e permanência estudantil. Na segunda seção, são abordadas ações que criam condições de permanência para que os alunos possam manter-se na escola e concluir seus estudos com êxito. Na terceira seção, são apresentados alguns trabalhos elaborados por discentes do IFSP que convergem para ações destinadas a reduzir a evasão e considerações para promover a permanência estudantil.

O IFSP existe há mais de 110 anos e passou por diversas transformações. A última, ocorrida em 29 de dezembro de 2008, pela Lei Federal n. 11.892, cria o IFSP, equiparando os Institutos Federais (IFs) às universidades federais e consolidando as características pluricurriculares e de multicampi. É uma autarquia e oferece diversas modalidades de ensino profissionalizante: técnico (integrado, concomitante ou subsequente); graduação tecnológica; bacharelado; licenciaturas; pós-graduação stricto sensu e lato sensu, assim como cursos rápidos abertos à comunidade (Proeja[5] e FIC[6]) e cursos na modalidade Educação a distância (EaD), que consolidam a verticalização[7] do ensino profissional. O IFSP conta atualmente com 37 unidades, no estado de São Paulo, e oferece 801 cursos distintos, com 62.660 alunos regularmente matriculados (PNP, 2020).

De forma geral, a evasão estudantil é um problema enfrentado no IFSP e aqui é "compreendida como um fenômeno social complexo, definido como a interrupção no ciclo de estudos" (BAGGI; LOPES, 2011, p. 370 apud DAROS, 2015, p. 352). Desta 
forma, para o estudo da permanência, é necessário compreender os motivos da evasão escolar (DORE; LÜSCHER, 2011).

\section{ENTENDENDO A EVASÃO PARA PROMOVER A PERMANÊNCIA ESTUDANTIL}

A evasão estudantil pode ser demonstrada de várias formas, que vão desde a simples contagem das matrículas realizadas até auditorias de órgãos de controle das contas públicas. O Tribunal de Contas da União (TCU), após uma fiscalização efetuada no IFSP (exercício 2011), apontou taxas de conclusão nos cursos na ordem de " $46,8 \%$ para o médio integrado, 37,5\% para o Proeja, 25,4\% para a Licenciatura, 27,5\% para o Bacharelado e 42,8\% para os cursos de tecnólogo" (TCU, 2013, p. 2 apud DAROS, 2013, p. 94), indicando evasão em diversos cursos. Esse controle implicou a chamada dos responsáveis para tomarem providências por meio do Acórdão TCU $n^{\circ} 506$, de 13 de março de 2013.

Daros (2013, p. 100) coletou os motivos da evasão dos alunos dos campi que mantinham essas informações (Quadro 1).

Quadro 1 - Principais motivos da evasão levantados por campus do IFSP entre 2009 e 2013.

\begin{tabular}{|l|l|l|l|}
\hline Principais Motivos da Evasão & Metodologia & Ano & Campus \\
\hline $\begin{array}{l}\text { Horário de trabalho; dificuldades } \\
\text { de aprendizagem; problemas } \\
\text { familiares }\end{array}$ & $\begin{array}{l}\text { Questionário no } 2013 \\
\text { momento de saída } \\
\text { do estudante }\end{array}$ & Araraquara \\
\hline $\begin{array}{l}\text { Problemas no trabalho (mudança } \\
\text { de horário e horas extras); sem } \\
\text { identificação com o curso; } \\
\text { dificuldade no aprendizado }\end{array}$ & $\begin{array}{l}\text { Questionário no } \\
\text { momto de saída }\end{array}$ & & \\
\hline
\end{tabular}

RC: 94514

Disponível em: https://www.nucleodoconhecimento.com.br/educacao/instituto-federal 


\begin{tabular}{|c|c|c|c|}
\hline $\begin{array}{l}\text { Fator externo ao ambiente } \\
\text { escolar (saúde, dificuldade } \\
\text { financeira, falta de tempo para os } \\
\text { estudos); dificuldades com a } \\
\text { metodologia de ensino; } \\
\text { dificuldades na relação professor- } \\
\text { aluno }\end{array}$ & $\begin{array}{l}\text { Questionário no } \\
\text { momento de saída } \\
\text { do estudante e } \\
\text { depoimentos dos } \\
\text { estudantes evadidos }\end{array}$ & 2011 & Itapetininga \\
\hline $\begin{array}{l}\text { Horário de trabalho incompatível; } \\
\text { passou no vestibular em outras } \\
\text { instituições; não se identificou } \\
\text { com o curso }\end{array}$ & $\begin{array}{l}\text { Consulta aos dados } \\
\text { da secretaria }\end{array}$ & 2012 & Hortolândia \\
\hline $\begin{array}{l}\text { Não conseguiu conciliar trabalho } \\
\text { com o curso; dificuldade de } \\
\text { acompanhar o curso }\end{array}$ & $\begin{array}{l}\text { Questionário no } \\
\text { momento de saída } \\
\text { do estudante }\end{array}$ & 2009 & $\begin{array}{l}\text { São João da } \\
\text { Boa Vista }\end{array}$ \\
\hline $\begin{array}{l}\text { Trabalho; incompatibilidade com } \\
\text { o curso; mudança para outros } \\
\text { cursos }\end{array}$ & $\begin{array}{l}\text { Questionário no } \\
\text { momento de saída } \\
\text { do estudante }\end{array}$ & $\begin{array}{l}2013 \\
1^{\circ}- \\
\text { semestre }\end{array}$ & Sertãozinho \\
\hline
\end{tabular}

Fonte: Daros (2013, p. 100).

Observa-se que para Daros (2013) realizar uma pesquisa a fim de mapear os principais motivos da evasão escolar, teve-se como motivação o acórdão do TCU e que a pesquisadora se baseou em documentações existentes de campi que mantinham registros do motivo de abandono do aluno. Os motivos relatados são de cunho pessoal/familiar e poucos como fatores internos à escola.

Em outro estudo, Santos (2018) se propõe a pesquisar a democratização do acesso aos Institutos Federais, focando na lei das cotas, mas esclarece a autora, que se preocupa em saber "em que medida a ampliação da oferta de vagas e a política de reserva de vagas contribuíram, ou não, para a maior democratização do acesso a essa modalidade especial de ensino médio, o EMI?". Assim, a pesquisa de Santos RC: 94514

Disponível em: https://www.nucleodoconhecimento.com.br/educacao/instituto-federal 
(2018) abrange este tema de forma mais completa de onde sintetizamos alguns motivos da evasão em outras unidades da Educação Profissional Técnica de Nível Médio (EPTNM) dos IFs (Quadro 2).

Quadro 2 - Pesquisas sobre evasão em unidades de Institutos Federais

\begin{tabular}{|c|c|c|c|}
\hline $\begin{array}{l}\text { Instituto } \\
\text { Federal }\end{array}$ & Autor & Cursos & Causas \\
\hline $\begin{array}{l}\text { Instituto } \\
\text { Federal do } \\
\text { Triângulo } \\
\text { Mineiro }\end{array}$ & $\begin{array}{l}\text { Piedade, } \\
2017\end{array}$ & $\begin{array}{l}\text { Eletrotécnica; } \\
\text { Logística; } \\
\text { Mineração }\end{array}$ & $\begin{array}{l}\text { Questões pessoais e } \\
\text { vocacionais; Fatores estruturais } \\
\text { e administrativos da escola; e } \\
\text { Fatores didático-pedagógicos }\end{array}$ \\
\hline $\begin{array}{l}\text { Instituto } \\
\text { Federal } \\
\text { Norte de } \\
\text { Minas } \\
\text { Gerais }\end{array}$ & Silva, 2017 & $\begin{array}{l}\text { Química; } \\
\text { Informática }\end{array}$ & $\begin{array}{l}\text { Fatores ligados ao aprendizado } \\
\text { e às disciplinas }\end{array}$ \\
\hline $\begin{array}{l}\text { Instituto } \\
\text { Federal } \\
\text { Norte de } \\
\text { Minas } \\
\text { Gerais }\end{array}$ & $\begin{array}{l}\text { Gomes e } \\
\text { Laudares, } \\
2016\end{array}$ & Enfermagem & $\begin{array}{l}\text { Trabalho; } \\
\text { Mobilidade/dificuldade de } \\
\text { transporte }\end{array}$ \\
\hline $\begin{array}{l}\text { Instituto } \\
\text { Federal de } \\
\text { Brasília }\end{array}$ & $\begin{array}{l}\text { Silva; Dias e } \\
\text { Silva, } 2015\end{array}$ & $\begin{array}{l}\text { Eventos; Informática; } \\
\text { e Serviços Públicos }\end{array}$ & Renda \\
\hline $\begin{array}{l}\text { Instituto } \\
\text { Federal de } \\
\text { Santa } \\
\text { Catarina }\end{array}$ & $\begin{array}{l}\text { Sais } \quad \text { e } \\
\text { Vieira, } 2016\end{array}$ & $\begin{array}{l}\text { Edificações; } \\
\text { Eletrotécnica }\end{array}$ & $\begin{array}{l}\text { Incompatibilidade } \\
\text { trabalho e estudo (falta de } \\
\text { tempo para estudar, baixa } \\
\text { renda e problema de } \\
\text { transporte) }\end{array}$ \\
\hline
\end{tabular}

RC: 94514

Disponível em: https://www.nucleodoconhecimento.com.br/educacao/instituto-federal 


\begin{tabular}{|c|c|c|c|}
\hline $\begin{array}{l}\text { Instituto } \\
\text { Federal de } \\
\text { Santa } \\
\text { Catarina }\end{array}$ & $\begin{array}{l}\text { Padoin } \quad \text { e } \\
\text { Amorim, } \\
2015\end{array}$ & $\begin{array}{l}\text { Telecomunicações; e } \\
\text { Refrigeração/Ar- } \\
\text { condicionado }\end{array}$ & $\begin{array}{l}\text { Falta de identificação com o } \\
\text { curso foi o fator mais apontado }\end{array}$ \\
\hline Cefet-RJ & $\begin{array}{l}\text { Figueiredo, } \\
2014\end{array}$ & Telecomunicações & $\begin{array}{l}\text { Lacunas na escolha do curso; } \\
\text { Fatores escolares; Dificuldades } \\
\text { pessoais; Influência de amigos; } \\
\text { Oportunidades e desinteresse } \\
\text { institucional } \\
\text { governamental }\end{array}$ \\
\hline
\end{tabular}

Fonte: Santos (2018, p. 162).

Pode-se perceber que nestes casos apontados por Santos (2018), surgem os fatores pessoais/familiares, questões internas à escola e questões de baixa renda/recursos para permanecer nos estudos.

Com intuito de obter mais informações a respeito dos motivos que levam os alunos a abandonar seus cursos, buscamos na pesquisa de Lins (2021) um quadro similar no qual a autora exemplifica alguns motivos da evasão escolar, reproduzidos no Quadro 3.

Quadro 3 - Fatores que contribuíram para a evasão em cursos técnicos de nível médio

\begin{tabular}{|l|l|l|}
\hline Autor(es) & $\begin{array}{l}\text { Instituição } \\
\text { Pesquisada }\end{array}$ & $\begin{array}{l}\text { Fatores que contribuíram para evasão no(s) } \\
\text { curso(s) }\end{array}$ \\
\hline $\begin{array}{l}\text { Andrade et al. } \\
\text { (2015) }\end{array}$ & CEFET-MG & $\begin{array}{l}\text { Aprovação para o ensino superior, atividade } \\
\text { profissional em área diferente do curso escolhido, } \\
\text { situação socioeconômica, falta de afinidade com } \\
\text { o curso, problemas familiares e dificuldades em } \\
\text { conciliar trabalho e escola. }\end{array}$ \\
\hline
\end{tabular}

RC: 94514

Disponível em: https://www.nucleodoconhecimento.com.br/educacao/instituto-federal 


\begin{tabular}{|c|c|c|}
\hline $\begin{array}{l}\text { Matos, } \\
\text { Vasconcelos e } \\
\text { Santos (2015) }\end{array}$ & IFTO & $\begin{array}{l}\text { Fatores individuais: dificuldade de adaptação da } \\
\text { estrutura curricular, indisciplina, problemas de } \\
\text { saúde, gravidez, deficiência, dependentes de } \\
\text { substância psicoativas. } \\
\text { Fatores internos: corpo docente, infraestrutura e } \\
\text { qualificação insuficientes. Ausência de } \\
\text { professores e falta de refeitório no campus. } \\
\text { Fatores externos: desinteresse pelas atividades } \\
\text { escolares, desconhecimento da estrutura } \\
\text { curricular, desemprego dos familiares, violência, } \\
\text { falta de transporte urbano e intermunicipal. }\end{array}$ \\
\hline $\begin{array}{l}\text { Oliveira et al. } \\
(2015)\end{array}$ & IFRJ & $\begin{array}{l}\text { Vulnerabilidade socioeconômica; dificuldade de } \\
\text { conciliar trabalho e estudo; expectativas não } \\
\text { atendidas pelo curso; transferência; reprovações } \\
\text { nos primeiros períodos; currículos "inchados"; } \\
\text { certificação pelo ENEM e docentes sem formação } \\
\text { pedagógica. }\end{array}$ \\
\hline $\begin{array}{l}\text { Queiroz, } \\
\text { Brandão } \\
\text { Santos (2015) }\end{array}$ & IFPE & $\begin{array}{l}\text { Trabalho; não identificação com o curso; entrada } \\
\text { no ensino superior; motivos familiares. }\end{array}$ \\
\hline Silva (2015) & IFTO & $\begin{array}{l}\text { Problemas de aprendizagem ou dificuldades nas } \\
\text { disciplinas (em especial matemática, física e } \\
\text { química); repetência; dificuldade de } \\
\text { relacionamento do estudante (com professor ou } \\
\text { colega de sala); frustração de expectativas em } \\
\text { relação ao curso; fatores como horário e carga } \\
\text { horária do curso; excesso de disciplinas; } \\
\text { formação precária do ensino fundamental; }\end{array}$ \\
\hline
\end{tabular}

RC: 94514

Disponível em: https://www.nucleodoconhecimento.com.br/educacao/instituto-federal 
motivação, interesse ou compromisso com o curso.

Fonte: Jardim (2016, p. 40 apud LINS, 2021, p. 9)

Observam-se no Quadro 1 (dados pesquisados antes de 2013) e nos Quadros 2 e 3 (dados de 2014 a 2017), que os motivos/causas da saída do estudante do curso/escola se mesclam entre questões pessoais, sociais e institucionais. Essa situação dialoga com estudos de Dore e Luscher (2011); e Figueiredo e Salles (2017).

Santos (2018, p. 161) considera que "é primordial identificar as causas da evasão, ainda que essa não seja uma tarefa fácil, em razão do seu caráter complexo, dinâmico e multifacetado".

Nesse contexto, Lins (2021) em sua pesquisa sobre os fatores causadores da evasão escolar ressalta que:

Em termos de resultados, como fatores que ocasionam a evasão, a pesquisa teve os seguintes resultados: fatores individuais (questões psicológicas); fatores internos à instituição (problemas nas questões didático-pedagógicas) e fatores externos à instituição (dificuldades em algumas disciplinas, formação precária no ensino fundamental e questões socioeconômicas). (LINS, 2021, p. 2).

Observando ser algo complexo, dinâmico e multifacetado, que envolvem fatores individuais do estudante e/ou internos à instituição de ensino e/ou externos a esta, nos governos de Luiz Inácio Lula da Silva (2003-2010) e Dilma Vana Rousseff (20112016), buscou-se trabalhar a desigualdade social que acarretava dificuldades de ingresso e permanência do aluno na escola, com leis e decretos que foram sancionados para melhorar o acesso e dar condições de permanência para que estudantes socialmente vulneráveis pudessem concluir seus estudos.

A própria criação dos IFs foi uma estratégia para que mais adolescentes e jovens tivessem acesso à Educação e, entre outras ações, foram sancionados os seguintes dispositivos legais: Decreto n. 7.234, de 19 de julho de 2010, que cria o Programa

RC: 94514

Disponível em: https://www.nucleodoconhecimento.com.br/educacao/instituto-federal 
Nacional de Assistência Estudantil (Pnaes) e a Lei n. 12.711, de 29 de agosto de 2012, que estipula as cotas sociais e raciais para o ingresso nas Universidades e Institutos Federais, possibilitando que mais jovens e adolescentes acessem uma escola pública.

Lins (2021, p. 21) considera que fatores pessoais/familiares possuem grande peso na decisão do aluno em continuar ou não seus estudos, porém questões socioeconômicas também são significativas para a evasão escolar e que "faz-se imprescindível que a instituição favoreça, através de seus Programas de Assistência Estudantil, a permanência de um maior quantitativo de discentes que não dispõem de recursos financeiros suficientes". Daros (2013); Antunes (2018) e Silva e Haas (2019) descrevem e analisam a implementação do Pnaes nas Instituições Federais de Ensino Superior (Ifes) e como, nesse processo, foram desenvolvidos procedimentos que beneficiassem estudantes em situação de vulnerabilidade. Daros (2013, p. 87) tece críticas à "bolsificação da assistência estudantil", e afirma que a transferência de renda, com caráter focalista e não universalista, dificulta para que "o atendimento aos estudantes seja ampliado, as ações não são traduzidas apenas em programas e auxílios, mas em projetos ampliados de assistência estudantil, como a construção de moradias e restaurantes universitários, que possibilitam o atendimento de maior número de estudantes".

Santos (2018) apresenta como a democratização do acesso aos IFs beneficia muitos adolescentes e jovens, os quais, sem a lei das cotas raciais, não teriam oportunidade de frequentar uma escola pública. No caso específico dos IFs, os alunos da EPTNM também são elegíveis a participar do Pnaes, pois os IFs possuem autonomia administrativa para oferecer esse programa também no nível médio.

Desde 2017, as Taxas de Evasão Estudantil no IFSP são dimensionadas e divulgadas anualmente, pela PNP, e registra uma redução de 2017 a 2019, na maioria dos cursos, com exceção do mestrado profissional (Tabela 1).

RC: 94514

Disponível em: https://www.nucleodoconhecimento.com.br/educacao/instituto-federal 
Tabela 1 - Taxas de evasão estudantil no IFSP de 2017 a 2019

\begin{tabular}{|l|l|l|l|}
\hline Cursos & $\mathbf{2 0 1 7}$ & $\mathbf{2 0 1 8}$ & $\mathbf{2 0 1 9}$ \\
\hline Média Geral & $\mathbf{2 8 , 0 0 \%}$ & $\mathbf{2 4 , 3 0 \%}$ & $\mathbf{2 1 , 8 0 \%}$ \\
\hline Qualificação Profissional (FIC) & $43,60 \%$ & $44,70 \%$ & $41,50 \%$ \\
\hline Técnico & $19,40 \%$ & $15,60 \%$ & $14,80 \%$ \\
\hline Bacharelado & $10,50 \%$ & $8,70 \%$ & $10,30 \%$ \\
\hline Licenciatura & $16,60 \%$ & $15,90 \%$ & $15,60 \%$ \\
\hline Tecnologia & $16,40 \%$ & $16,50 \%$ & $14,50 \%$ \\
\hline Especialização (lato sensu) & $17,50 \%$ & $19,50 \%$ & $15,60 \%$ \\
\hline Mestrado & $0,00 \%$ & $0,00 \%$ & $0,00 \%$ \\
\hline Mestrado Profissional & $10,00 \%$ & $8,30 \%$ & $13,00 \%$ \\
\hline
\end{tabular}

Fonte: PNP (2017; 2018; 2019).

As maiores taxas de evasão ocorrem nos cursos de qualificação profissional da formação inicial e da continuada. Nos demais cursos, ocorrem oscilações, que não ultrapassam os $20 \%$, mas necessitam ser analisadas. Existem outros fatores, além da desigualdade social, que devem ser analisados, pois se inter-relacionam com a ocorrência da evasão estudantil.

Dore e Lüscher (2011), que se apoiam nos conceitos de Rumberger[8], descrevem que, além das desigualdades sociais, características, em parte, individuais/comunitárias do estudante, a decisão entre evadir ou permanecer na escola passa por outras perspectivas institucionais, que, por sua vez, se desdobram em fatores, conforme exemplificado no Quadro 2 do estudo de Santos (2018).

Cislaghi (2008) identifica os fatores que levam à evasão ou permanência do aluno na escola e apresenta um modelo de sistema de gestão do conhecimento voltado a diminuir a evasão e promover a permanência. $O$ autor levanta causas para a evasão e analisa modelos desenvolvidos por acadêmicos[9], considerando que a análise desses modelos:

RC: 94514

Disponível em: https://www.nucleodoconhecimento.com.br/educacao/instituto-federal 
[...] propicia a compreensão da uma estreita inter-relação entre quatro termos: evasão, o fenômeno; desgaste, como um processo longitudinal que pode demover um estudante de sua iniciativa de obter uma formação de nível superior; permanência, como o objetivo final de um conjunto de políticas e programas institucionais para manter um estudante e, também, como a resultante de diversos fatores que levam o estudante decidir permanecer num curso superior no qual ingressou (CISLAGHI, 2008, p. 66).

A partir dos modelos analisados, Cislaghi (2008) relaciona a decisão do estudante entre evadir-se ou permanecer, a três esferas, nas quais o discente se insere: o individual, o seu coletivo e o da instituição que optou por frequentar. No modelo elaborado por Cislaghi (2008), é possível ver as inter-relações do estudante nos ambientes em que se encontra inserido (Figura 1).

Figura 1 - Modelo das interações estudante-escola-comunidade para o estudo da permanência estudantil.

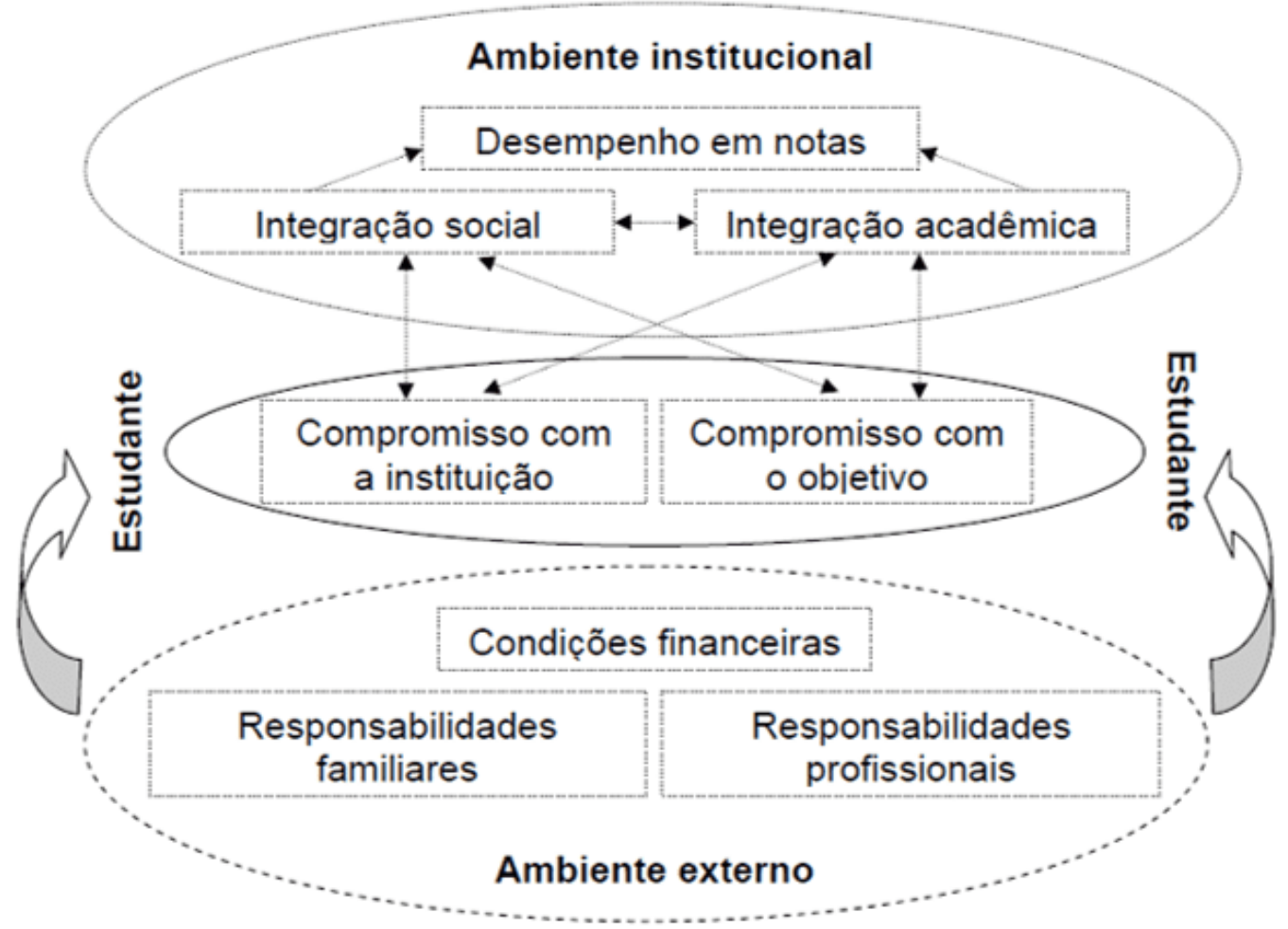

Fonte: Cislaghi (2008, p. 74).

RC: 94514

Disponível em: https://www.nucleodoconhecimento.com.br/educacao/instituto-federal 


\section{A PERMANÊNCIA ESTUDANTIL E SUAS VARIÁVEIS}

Permanência estudantil é o ato de o aluno reunir condições de manter-se na escola e concluir seus estudos com êxito. Não estão sendo consideradas como extensão da permanência na escola a modalidade período integral ou os casos de alunos várias vezes retidos e que continuam por mais anos na escola, até finalizar os estudos.

A Constituição Federal (CF) de 1988 trouxe melhorias, para a área da Educação, que já vinham sendo pleiteadas há anos; dentre elas, destacam-se "A educação, direito de todos e dever do Estado e da família, será promovida e incentivada com a colaboração da sociedade, visando ao pleno desenvolvimento da pessoa, seu preparo para o exercício da cidadania e sua qualificação para o trabalho" (Art. 205) e que "O ensino será ministrado com base nos seguintes princípios:" (Art. 206) "igualdade de condições para o acesso e permanência na escola" (inciso I, grifo nosso).

Mesmo antes de promulgada a CF de 1988, ações governamentais, como programas de alimentação escolar (merenda); material didático; transporte escolar; bolsas de ensino; entre outras, já vinham sendo praticadas para garantir a permanência e, no período pós-CF de 1988, passou-se a lutar por novas estratégias possíveis, para proporcionar condições de igualdade de acesso e permanência. $O$ Pnaes é uma delas. O Programa foi instituído por meio da Portaria Normativa n. 39, de 12 de dezembro de 2007, assinada pelo então ministro de Educação, Fernando Haddad:

no uso de suas atribuições, considerando a centralidade da assistência estudantil como estratégia de combate às desigualdades sociais e regionais, bem como sua importância para a ampliação e a democratização das condições de acesso e permanência dos jovens no ensino superior público federal (MEC, 2007, p. 1, grifos nossos).

Essa conquista é alcançada depois de anos de contestações feitas por membros da sociedade civil; União Nacional dos Estudantes (UNE); Associação Nacional dos Dirigentes das Instituições Federais de Ensino Superior (Andifes); e do Fórum Nacional de Pró-reitores de Assuntos Comunitários e Estudantis (Fonaprace). 
Materializa-se, inicialmente, por meio do Plano Nacional de Assistência Estudantil sugerido pela Andifes ao Ministério da Educação (MEC) e que se transformou na Portaria n. 39/2007. No documento, a assistência estudantil deveria trabalhar com as seguintes áreas: I - moradia estudantil; II - alimentação; III - transporte; IV assistência à saúde; V - inclusão digital; VI - cultura; VII - esporte; VIII - creche e IX - apoio pedagógico (MEC, 2007).

Em 2010, o Pnaes é institucionalizado pelo Decreto federal n. 7.234, de 19 de julho de 2010 que, conforme estabelecido, foi implementado nas Ifes, assim como na EPTNM, que fazem parte dos IFs. A assistência estudantil é composta pelo Programa de Auxílio Permanência e pelo Programa de Ações Universais.

Apesar de ter sido implementado e estar concedendo assistência estudantil por meio de Política de Assistência Estudantil (PAE), com ações universais e focalizadas, devese esclarecer que autores como Leite (2012; 2015); Dutra e Santos (2017) e Daros (2013), debatem o caráter focalizado da concessão desse benefício e se essa ação cumpre os fins estudantis ou se transforma em assistência social. Para Leite (2012, p. 470), "abordar a assistência na sua forma mais aparente: como ajuda pontual e personalizada aos grupos de maior 'vulnerabilidade social' [...] a expressão 'vulnerabilidade social', embora seja a correntemente utilizada, vitimiza os indivíduos, escamoteando sua verdadeira gênese".

Daros (2013, p. 87) esclarece que "os institutos federais e as universidades têm optado pela chamada 'bolsificação da assistência estudantil', que nada mais é do que a transferência de renda realizada aos estudantes por intermédio dos auxílios alimentação, transporte, moradia, creche, dentre outros".

Para Leite (2015, p. 425), "a transferência direta de renda por meio de auxílios financeiros (pecúnia) desvirtua os princípios da assistência estudantil", passando a se assemelhar a uma ação de assistência social.

RC: 94514

Disponível em: https://www.nucleodoconhecimento.com.br/educacao/instituto-federal 
Considerando que o Pnaes foi inicialmente concebido para "garantir o acesso, a permanência e a conclusão de curso dos estudantes das Ifes, na perspectiva da inclusão social, de melhoria do desempenho acadêmico e de qualidade de vida" (ANDIFES, 2007, p. 2), entende-se que:

[...] a compreensão da assistência enquanto investimento, apesar do mérito de tentar romper com ideário dominante na época que a concebia como um gasto aponta para uma concepção produtivista desse objeto, dando as bases para a incorporação de um sentido de retorno, de contrapartida, de funcionalidade. (NASCIMENTO, 2013 apud DUTRA; SANTOS, 2017, p. 162).

Para Leite (2015, p. 464), "uma política de assistência ao estudante não pode se limitar a criar e executar mecanismos destinados à população de baixa renda; ela deve, também, se preocupar com princípios de atendimento universal".

Para analisar outras ações de permanência, recorreu-se a Mendes (2020), que aborda a produção bibliográfica sobre permanência estudantil realizada entre 1987 e 2019 . O levantamento abrangeu 230 dissertações de mestrado; 35 teses de doutorado; e 36 artigos publicados em periódicos. A área da Educação foi a mais explorada, com 98 trabalhos, seguida pelo Serviço Social, com 58; Administração, com 31; Psicologia, com 18; políticas públicas, com 14; estudos interdisciplinares, com 13; e Economia, com 12 trabalhos. Por fim, Mendes (2020, p. 403) considera que "pesquisas que envolvam servidores da instituição são ainda pouco numerosas, e poderiam contribuir para uma operacionalização mais efetiva da política de permanência estudantil".

Santos et al. (2020) em seu trabalho de pesquisa traçou o perfil dos estudantes evadidos do curso Técnico em Edificações, na modalidade subsequente, do IFMG Campus Piumhi. Foi realizado um estudo analítico-descritivo, através de um levantamento de dados oriundos da secretaria acadêmica da instituição. Relatam as autoras que "este estudo confirmou o quão complexo e abrangente é o problema da evasão por ela ser "silenciosa" e pela pluralidade de suas causas que podem estar ligadas a fatores internos e externos ao ambiente escolar." (SANTOS et al., 2020, p. 
12). Além de corroborar com os estudos de Daros (2013), Santos (2018) e Lins (2021), Santos et al. (2020) sugere que:

\begin{abstract}
Trata-se de um problema que precisa ser discutido e combatido com medidas preventivas que possibilitem a integração do aluno no espaço formativo do IFMG. Acredita-se que possa ajudar no combate à evasão: a criação de um restaurante universitário (visto que o custo para a alimentação dos alunos seria menor), a melhoria das políticas de assistência estudantil (devido a diversidade de renda dos alunos e das condições menos favoráveis de alguns), o crescimento da oferta de monitoria aos estudantes (uma vez que se o aluno tiver concluído o ensino médio à um tempo expressivo, pode ser que tenha uma maior dificuldade nas disciplinas do curso), auxílio pedagógico e psicológico, cursos de nivelamento, entre outras. (SANTOS et al., 2020, p. 13).
\end{abstract}

Observa-se que, assim como existem vários motivos para a evasão, deve-se analisálos e transformá-los em ações que deem condições ao estudante de permanecer na escola e concluir seus estudos, como sugerido por Santos et al. (2020).

\title{
4. QUEM ESTÁ REFLETINDO SOBRE A PERMANÊNCIA ESTUDANTIL NO IFSP
}

Em pesquisa bibliográfica com as palavras-chave 'permanência' e 'evasão', realizada pelo sistema Pergamum, da biblioteca do IFSP, no período de 2012 a 2021, foram identificados 13 trabalhos de autoria de servidores e discentes do IFSP (Quadro 3). Desses, oito eram de discentes (62\%). As assistentes sociais foram as servidoras que mais realizaram estudos (três deles).

Quadro 3 - Autores de trabalhos abordando evasão e permanência com vínculo com o IFSP

\begin{tabular}{|l|l|l|}
\hline Autor & Vínculo com o IFSP & Campus \\
\hline $\begin{array}{l}\text { ALMEIDA, Francisco } \\
\text { Antonio }\end{array}$ & Docente de Informática & Barretos \\
\hline
\end{tabular}

RC: 94514

Disponível em: https://www.nucleodoconhecimento.com.br/educacao/instituto-federal 


\begin{tabular}{|c|c|c|}
\hline $\begin{array}{l}\text { DANTAS, Maria } \\
\text { Conceição Borges }\end{array}$ & Assistente Social & São Paulo \\
\hline $\begin{array}{l}\text { DAROS, Michelli } \\
\text { Aparecida }\end{array}$ & Assistente Social & Reitoria \\
\hline $\begin{array}{l}\text { HERMÓGENES, } \\
\text { Natasha Silva Pires }\end{array}$ & $\begin{array}{l}\text { Discente de Licenciatura em Física. } \\
\text { Orientador: Prof. Jucivagno Francisco } \\
\text { Cambuhy Silva }\end{array}$ & São Paulo \\
\hline $\begin{array}{l}\text { LEITE, } \quad \text { Karina } \\
\text { Priscila } \\
\text { Pinto }\end{array}$ & Discente de Pós-graduação Prof EPT & Sertãozinho \\
\hline $\begin{array}{l}\text { MATUMOTO, } \\
\text { Carolina Ayumi }\end{array}$ & $\begin{array}{l}\text { Discente de Tecnologia em Análise e } \\
\text { Desenvolvimento de Sistemas. } \\
\text { Orientador: Prof. Vitor Brandi Junior }\end{array}$ & Capivari \\
\hline $\begin{array}{l}\text { MOURA, Marta } \\
\text { Alves de Lima }\end{array}$ & $\begin{array}{l}\text { Discente de Licenciatura em Matemática. } \\
\text { Orientadora: Profa. Dra. Natália Nassiff } \\
\text { Braga }\end{array}$ & Caraguatatuba \\
\hline $\begin{array}{l}\text { NORBERTO, Juliana } \\
\text { Alvim }\end{array}$ & Técnica em Assuntos Educacionais & $\begin{array}{ll}\text { São } & \text { Miguel } \\
\text { Paulista } & \end{array}$ \\
\hline $\begin{array}{l}\text { PEREIRA, Daiane } \\
\text { Galvão }\end{array}$ & $\begin{array}{l}\text { Discente de Tecnologia em Sistemas } \\
\text { para Internet. Orientador: Prof. Ricardo } \\
\text { Alexandre Neves; Coorientador: Prof. } \\
\text { Gustavo Aurélio Prieto }\end{array}$ & $\begin{array}{l}\text { São João da } \\
\text { Boa Vista }\end{array}$ \\
\hline $\begin{array}{l}\text { RIBEIRO, Aline Pires } \\
{[10]}\end{array}$ & $\begin{array}{l}\text { Discente de Bacharelado em } \\
\text { Administração. Orientadora: Profa. Dra. } \\
\text { Renata Plaza Teixeira }\end{array}$ & Jacareí \\
\hline $\begin{array}{l}\text { SANTOS, Danielle } \\
\text { de Souza }\end{array}$ & Pedagoga & Reitoria \\
\hline
\end{tabular}

RC: 94514

Disponível em: https://www.nucleodoconhecimento.com.br/educacao/instituto-federal 


\begin{tabular}{|ll|l|l|}
\hline $\begin{array}{l}\text { SANTOS, Thais } \\
\text { Cristina }\end{array}$ & $\begin{array}{l}\text { Discente de Bacharelado em } \\
\text { Administração. Orientadora: Profa. Dra. } \\
\text { Renata Plaza Teixeira }\end{array}$ & Jacareí \\
$\begin{array}{l}\text { SILVA, Ana Rita } \\
\text { Dantas }\end{array}$ & $\begin{array}{l}\text { Assistente Social } \\
\text { SILVA, Paula } \\
\text { Eduarda Soares da }\end{array}$ & $\begin{array}{l}\text { Discente de Técnico em Automação } \\
\text { Industrial. Orientador: Prof. Dr. Leonardo } \\
\text { Borges da Cruz }\end{array}$ & \\
& Salto & \\
\hline
\end{tabular}

Fonte: Elaboração própria a partir da documentação bibliográfica pesquisada.

Ao analisar os trabalhos produzidos, observa-se que Almeida (2017); Hermógenes (2016); e Ribeiro e Santos (2021), abordam a evasão de alunos no curso Técnico de Informática do campus Barretos; curso de Licenciatura em Física do campus São Paulo; e no curso de Administração do campus Jacareí, respectivamente. A base teórica é convergente com o exposto na segunda seção deste artigo quando se aponta a diversidade de causas que levam o aluno a abandonar os estudos e que estas podem ser classificadas em fatores pessoais, externos e internos à instituição escolar. Há reflexões desses autores com alternativas para minimizar esse problema.

$\mathrm{Na}$ conclusão de seu trabalho, Almeida (2017, p. 129-130) sumariza as principais causas da evasão e sugere que "algumas ações de intervenção para combate e redução da evasão e retenção, minimizando o insucesso de aprendizado dos alunos e que poderão ser instituídas pelo IFSP Brt[11] são:

- Estudar a possibilidade de fazer atualização ou readequação no Projeto Pedagógico do Curso para flexibilizar a dependência de dois ou três componentes curriculares e efetivar uma maior integração entre as disciplinas do núcleo comum com as do núcleo técnico;

- Aumentar o horário de atendimento dos professores aos alunos com dificuldades de acompanhamento das disciplinas

RC: 94514

Disponível em: https://www.nucleodoconhecimento.com.br/educacao/instituto-federal 
objetivando sempre o resgate da aprendizagem. Tais dificuldades e carências de aprendizagem foram muito enfatizadas nos relatos dos discentes evadidos;

- Desenvolver atividades e ações de conscientização do estudante sobre a importância de incluir o estudo na sua rotina diária;

- Desenvolver um plano de estudo personalizado para os estudantes em situação de retenção ou risco de evasão segundo as possibilidades da instituição e de cada estudante;

- Realizar avaliação diagnóstica no início dos componentes curriculares para identificar possíveis deficiências de aprendizados dos estudantes e propor ações de intervenção pedagógica e andragógica pertinentes;

- Implementar ações objetivando um maior inter-relacionamento docente-aluno-escola-família para que os alunos se sintam parte integrante do IFSP Brt e tenham uma participação mais proativa na construção de seus aprendizados e no desenvolvimento de suas competências e habilidades técnicas exigidas pelo mercado de trabalho;

- Dentre outras ações que permita a recuperação e a reconstrução do aprendizado dos alunos. (grifos nossos).

Hermógenes (2016) não tece considerações sobre ações para promover a permanência, porém, percebe-se que, no estudo realizado, demanda mais ações para os fatores pessoais e internos à instituição.

Ribeiro e Santos (2021) consideram que reduzir os fatores de evasão estudantil no IFSP requer melhor preparo dos docentes em relação à didática e metodologia de ensino. Também elencam que fatores financeiros, comportamentais, sociais e geográficos influenciam a decisão do aluno em permanecer ou não na instituição.

RC: 94514

Disponível em: https://www.nucleodoconhecimento.com.br/educacao/instituto-federal 
Observa-se que, nos três casos analisados, para evitar a evasão, sugerem a participação de toda a comunidade escolar, pois as iniciativas requerem ações dos servidores e/ou departamentos, direta ou indiretamente envolvidos no processo, e da família.

Dantas (2015, p. 1-5) aborda a importância de ser traçado o perfil do aluno ingressante, para que "em posse dessas informações seja possível construir um processo permanente de revisão e reconstrução das práticas-pedagógicas, da gestão escolar, assim como dos serviços a serem ofertados a esses alunos". Conhecendo o perfil do aluno, a instituição, com todos os seus servidores, e/ou departamentos, devem criar condições "não só com a democratização do acesso desses alunos, mas também como políticas de permanência que se preocupem com esse processo de ambientação, integração e inclusão destes no IFSP”.

Daros (2013); Norberto (2019) e Santos (2018) dissertam a respeito da assistência estudantil, sua história e ligações de seus sujeitos. Daros (2013, p. 59) enaltece que, por meio da '“relação simbiótica' entre professores e estudantes, é possível compreender a especificidade da Educação, que está envolta aos conceitos, ideias, símbolos, hábitos, atitudes e conhecimento". Com o tempo, essa relação passou a ser considerada entre escola e aluno, pois, em uma nova "concepção emancipadora de educação e formação, avançou no sentido de buscar superar as dicotomias entre professores e especialistas, pedagogia e licenciaturas, especialistas e generalistas, pois a escola avançava para a democratização das relações de poder em seu interior" (DAROS, 2013, p. 63).

Os motivos que levam um aluno a abandonar seus estudos podem variar, mas, para Daros (2013, p. 111), é imprescindível que os sinais que antecedem a evasão sejam percebidos a tempo, para que "práticas investigativas de assistentes sociais, pedagogos, psicólogos e professores sejam intensificadas, a fim de compreender os motivos das faltas dos estudantes e buscar estratégias de intervenção". A partir do Pnaes, o Departamento Sociopedagógico estruturou-se para atender a todos os seus 
estudantes e, nas entrevistas realizadas, pela pesquisadora, com assistentes de outros campi, os principais elementos apresentados são assim resumidos:

a) O acolhimento ao estudante;

b) Ampliação da participação dos estudantes nas decisões da instituição;

c) Fortalecimento de atividades coletivas que estimulem o sentimento de pertencimento do estudante ao IFSP;

d) Abertura do IFSP à comunidade externa - para que os estudantes conheçam melhor os cursos antes de ingressar na instituição;

e) O acompanhamento social dos estudantes;

f) Identificação de situações que possam levar os estudantes evadirem-se dos cursos;

g) Estímulo às reflexões críticas e construção de novos saberes;

Suporte multidisciplinar envolvendo, principalmente, pedagogos, psicólogos, TAEs[12] e professores, além das assistentes sociais. (DAROS, 2013, p. 145).

Nota-se que existe uma chamada, do coletivo da instituição escolar, quando se pretende controlar a evasão e promover condições de permanência do aluno.

Para Norberto (2020, p. 80), a PAE é funcional, mas necessita de melhorias, pois "há uma tendência indicando que as normativas propostas para aplicação da PAE atingem parcialmente os objetivos propostos, porém, devem-se considerar as contradições do processo de efetivação dessa política". Corroboram com essa afirmação os problemas relatados pelos alunos e identificados pela pesquisadora (Quadro 4).

Quadro 4 - Problemas apontados pelos alunos

\begin{tabular}{l|l|l} 
Programa Nacional de & Desconhecimento da legislação nacional que \\
Assistência Estudantil (Pnaes) & regula as ações do Programa Nacional de
\end{tabular}

RC: 94514

Disponível em: https://www.nucleodoconhecimento.com.br/educacao/instituto-federal 


\begin{tabular}{|c|c|}
\hline & $\begin{array}{l}\text { Assistência Estudantil (Pnaes) - Decreto federal } \\
\text { n. } 7.234 \text {, de } 19 \text { de julho de } 2010\end{array}$ \\
\hline $\begin{array}{l}\text { Política de Assistência } \\
\text { Estudantil (PAE) do Instituto } \\
\text { Federal de Educação, Ciência e } \\
\text { Tecnologia de São Paulo (IFSP) }\end{array}$ & $\begin{array}{l}\text { Pouca compreensão dos objetivos e das } \\
\text { finalidades propostos pela Política de Assistência } \\
\text { Estudantil (PAE) do IFSP }\end{array}$ \\
\hline $\begin{array}{l}\text { Acesso aos atos normativos da } \\
\text { PAE do IFSP }\end{array}$ & $\begin{array}{l}\text { Desconhecimento do material disponível no } \\
\text { endereço oficial da Reitoria do IFSP com toda a } \\
\text { legislação e os atos normativos que regulam a } \\
\text { PAE do IFSP }\end{array}$ \\
\hline $\begin{array}{l}\text { Operacionalização para } \\
\text { recebimento de auxílio } \\
\text { financeiro }\end{array}$ & $\begin{array}{l}\text { Para os primeiros recebimentos, houve } \\
\text { desencontro de informações disponibilizadas } \\
\text { pelo IFSP sobre se o valor é depositado em conta } \\
\text { poupança ou retirado diretamente em agência } \\
\text { bancária, com ordem de pagamento } \\
\text { Inicialmente, houve divergência sobre a } \\
\text { obrigatoriedade de o aluno abrir conta poupança } \\
\text { em determinados bancos para recebimento dos } \\
\text { auxílios } \\
\text { Atraso no recebimento dos auxílios devido a } \\
\text { divergências nos dados bancários fornecidos } \\
\text { pelo aluno à administração do IFSP - SMP }\end{array}$ \\
\hline Agências bancárias & $\begin{array}{l}\text { No caso de recebimento por conta poupança, } \\
\text { houve desencontro de informações fornecidas } \\
\text { pelas agências bancárias referente à idade } \\
\text { mínima para abertura de conta sem o } \\
\text { responsável legal e cobrança de taxas para } \\
\text { manutenção das contas }\end{array}$ \\
\hline
\end{tabular}

RC: 94514

Disponível em: https://www.nucleodoconhecimento.com.br/educacao/instituto-federal 


\begin{tabular}{|l|l|}
\hline & $\begin{array}{l}\text { No caso de recebimento por ordem de } \\
\text { pagamento, existe divergência nos critérios para } \\
\text { retirada do valor nas agências de um mesmo } \\
\text { banco, como a obrigatoriedade de o aluno estar } \\
\text { acompanhado do responsável legal }\end{array}$ \\
\hline $\begin{array}{l}\text { Sistema Unificado da } \\
\text { Administração Pública (Suap) }\end{array}$ & $\begin{array}{l}\text { Atualizações realizadas no sistema indicando } \\
\text { mudanças na visualização e no } \\
\text { acompanhamento dos processos de seleção do } \\
\text { PAE do IFSP }\end{array}$ \\
\end{tabular}

Fonte: Norberto (2020, p. 80).

Santos (2018) discorre a respeito da democratização de acesso ao Ensino Médio Integrado (EMI) pela visão da Pedagogia, que trabalha com o sociopedagógico, e deve construir um caminho para que o aluno, ao conseguir acessar um curso no IFSP, permaneça e conclua seus estudos. Por outro lado, para Santos (2018, p. 209):

Não cabe, nos limites desta pesquisa, uma análise pormenorizada do fenômeno da evasão, mas deve-se ressaltar que ela é um dos grandes obstáculos à democratização dos cursos de EMI no IFSP. Isto posto, em concordância com os estudos do campo educacional, compreendemos que a evasão é um fenômeno complexo, multifacetado, dinâmico e relacional, nessa direção, destacamos a importância de superar as condições nem sempre favoráveis para que jovens permaneçam e concluam com êxito os cursos EMI.

Leite (2020) analisa a permanência dos alunos do curso Proeja, em Mecânica, no campus de Sertãozinho. O questionário da pesquisa foi encaminhado a 165 egressos do curso com perguntas dirigidas em relação aos fatores que contribuíram para que o aluno completasse o curso com sucesso. As respostas foram classificadas em fatores individuais, internos e externos ao curso. Para Leite (2020, p. 138), os resultados foram satisfatórios, visto que "no loco estudado (Campus Sertãozinho do IFSP) foi possível identificar que, ao longo dos anos, foram criadas diversas comissões internas, que visavam o acompanhamento da permanência e êxito dos estudantes". 
Matumoto (2018) e Pereira (2014) apresentam a construção de sistema e análise de dados que podem ser desenvolvidas para o controle da evasão estudantil. Matumoto (2018) considerou as informações existentes da evasão ocorrida nos cursos do campus Capivari e estruturou um sistema de modelagem utilizando a ferramenta WEKA[13] para auxiliar na detecção de sintomas de alunos que estejam prestes a evadir-se. Os dados de entrada são os fatores pessoais, internos e externos, relacionados à evasão. Após os testes, concluíram que:

Acima de fazer a pesquisa foi preciso entender os motivos que causam a evasão de um aluno, muitas vezes imperceptíveis quando não se tem muito contato direto com o mesmo. Principalmente quando é possível observar que características como sexo, etnia, idade e origem escolar tem um papel maior no perfil de evasão, conforme os resultados da pesquisa, o que condiz com o senso comum e a realidade dos cursos superiores na área de tecnologia. (MATUMOTO, 2018, p. 44).

Pereira (2014) apresenta uma proposta de Data Warehouse para análise da evasão escolar no campus São João da Boa Vista, que, por meio de informações do perfil do aluno, pode detectar sintomas de evasão, possibilitando ações de prevenção. Os testes mostraram-se satisfatórios, mas a pesquisadora recomenda que:

para trabalhos futuros, a fim de dar continuidade nesta pesquisa, a melhoria nos bancos de dados existentes (Acadêmico, Diário Eletrônico, do PAE e CPA) no sentido de refinar os relacionamentos e propor inovações para que estes possam atender outros requisitos.

Merece um destaque especial o banco de dados da Assistência Estudantil, pois este banco de dados atualmente é alimentado somente com o perfil dos alunos que procuram pelo benefício. A sugestão é que este banco de dados possa ser estendido para os demais alunos do campus para que se tenha um perfil social completo dos alunos. (PEREIRA, 2014, p. 102).

Moura (2017), discente do curso de licenciatura em Matemática, no campus Caraguatatuba, realiza um trabalho em que relaciona os dados da evasão escolar disseminados pelos órgãos oficiais do município com exercícios matemáticos que apontam para resultados diversos. Para estabelecimento do trabalho, Moura (2017) 
desenvolveu teoria da evasão escolar, gerando conhecimento e alertando os usuários desses dados.

\begin{abstract}
Essa discrepância apresentada foi discutida no trabalho de Kleine Ribeiro (1991), que teceram duras críticas ao sistema de dados estatísticos sobre educação no Brasil, principalmente no que se referem aos dados dos censos escolares.
\end{abstract}

No entanto, em relação aos censos escolares, é importante observar que há um problema anterior, que pode comprometer a levantamento de dados mesmo que os instrumentos de coleta estejam adequados. Trata-se dos próprios registros escolares, isto é, da maneira como são definidos e sistematizados os registros escolares sobre os diferentes eventos da vida escolar de cada aluno no ano letivo. (MOURA, 2017, p. 59).

Nesta seção, apontou-se que 14 autores apresentaram 13 trabalhos que envolvem a evasão e os fatores que auxiliam $o$ aluno a permanecer na escola. Independentemente dos objetivos e fatores que circunscrevem suas abordagens, a permanência escolar é tema de preocupação recorrente.

\title{
5. CONSIDERAÇÕES FINAIS
}

O objetivo deste trabalho foi conhecer textos produzidos por autores que mantêm vínculos com o IFSP e que abordam ações de permanência estudantil de alunos no Instituto como meio de reduzir a evasão. Considerando que a evasão estudantil significa perda para todos os envolvidos, pois o aluno que não conclui seus estudos participará do mercado de trabalho em situação de desvantagem, a escola passa a ter ociosidade em suas instalações; o professor não vê cumprida a sua tarefa de formar alunos; e o Estado perde no investimento feito nas escolas e por não formar profissionais que deveriam gerar benefícios para o país.

O referencial teórico mostrou a importância de serem estudados os fatores provocadores da evasão escolar para assim criar ações que deem condições a todos de acessar a escola em condições de igualdade; permanecer e concluir seus estudos com êxito.

RC: 94514

Disponível em: https://www.nucleodoconhecimento.com.br/educacao/instituto-federal 
Foram criados programas de assistência estudantil que vivam a garantir a permanência dos alunos, mas há outros fatores, além das questões de desigualdades sociais, que afetam a vida do estudante. Conhecer quais são esses fatores e como interagem na vida do estudante é importante, pois, a partir deles é que se pode pensar em ações que motivem a permanência do aluno na escola.

Quanto mais pessoas adquirirem esse conhecimento e trabalharem em conjunto, melhores serão as soluções para combater a evasão escolar.

Neste trabalho, foram identificados 14 pesquisadores que exploraram o tema da evasão com o objetivo de criar condições de permanência para seus alunos. Foi possível identificar nesta pesquisa que há outros servidores, no mesmo instituto, que compartilham da mesma preocupação.

O conhecimento gerado a partir deste estudo pode ser divulgado, para levar outros servidores a trabalharem com o tema. Para garantir a permanência escolar, é necessária a participação de todos os envolvidos no IF. A pesquisa mostrou, ainda, que poucos professores e servidores estudaram esse tema. E são os assistentes sociais os que mais analisaram o fenômeno. Assim, reflexões semelhantes podem contribuir para que a evasão escolar seja combatida e novos trabalhos surjam dentro do IFSP.

\section{REFERÊNCIAS}

ALMEIDA, Francisco Antonio de. A evasão escolar em uma unidade do IFSP no curso técnico em informática integrado na visão dos discentes evadidos: um estudo de caso da parceria IFSP e SEE-SP. Orientador: Prof. Dr. Darwin lanuskiewtz. 2017, 161p. Dissertação (Mestrado) - Programa de Pós-graduação em Educação: Processos de Ensino, Gestão e Inovação da Universidade de Araraquara (Uniara), Araraquara, 2017.

RC: 94514

Disponível em: https://www.nucleodoconhecimento.com.br/educacao/instituto-federal 
ANDIFES. Associação Nacional dos Dirigentes das Instituições Federais de Ensino Superior. Plano nacional de assistência estudantil. Brasília, 2007. Disponível em: https://www.andifes.org.br/wp-

content/files_flutter/Biblioteca_071_Plano_Nacional_de_Assistencia_Estudantil_da_ Andifes_completo.pdf. Acesso em: 14 jul. 2021.

ANTUNES, Evelise Dias. Assistência estudantil nos institutos federais: da política à implementação. Orientadora: Profa. Dra. Ana Elisa Spaolonzi Queiroz Assis. 2015, 272p. Dissertação (Mestrado) - Universidade Estadual de Campinas (Unicamp), Campinas, 2018.

BRASIL. [Constituição (1988)]. Constituição da República Federativa do Brasil. Brasília, 5 de outubro de 1988. Disponível em: www.planalto.gov.br/ccivil_03/constituicao/constituicaocompilado.htm. Acesso em: 20 jul. 2020.

BRASIL. Decreto federal n. 7.234, de 19 de julho de 2010. Dispõe sobre o Programa Nacional de Assistência Estudantil - Pnaes. Brasília, 2010a. Disponível em: http://www.planalto.gov.br/ccivil_03/_ato2007-

2010/2010/decreto/d7234.htm\#: :text=Decreto\%20n\%C2\%BA\%207234\&text=DECR ETO\%20N\%C2\%BA\%207.234\%2C\%20DE\%2019,que\%20lhe\%20confere\%200\%20 art.. Acesso em: 25 jul. 2020.

BRASIL. Lei federal n. 11.892, de 29 de dezembro de 2008. Institui a Rede Federal de Educação Profissional, Científica e Tecnológica, cria os Institutos Federais de Educação, Ciência e Tecnologia. Brasília, 2008b. Disponível em: http://www.planalto.gov.br/ccivil_03/_ato2007-2010/2008/lei/111892.htm. Acesso em: 16 jul. 2020.

BRASIL. Lei federal n. 12.711, de 29 de agosto de 2012. Dispõe sobre o ingresso nas universidades federais e institutos federais de ensino técnico de nível médio.

RC: 94514

Disponível em: https://www.nucleodoconhecimento.com.br/educacao/instituto-federal 
Brasília, 2012. Disponível em: http://www.planalto.gov.br/ccivil_03/_ato20112014/2012/lei/l12711.htm. Acesso em: 20 jul. 2021.

CISLAGHI, Renato. Um modelo de sistema de gestão do conhecimento em um framework para a promoção da permanência discente no ensino de graduação. Orientador Prof. Dr. Sílvio Serafim da Luz Filho, 2008, p. 273. Tese (Doutorado) Universidade Federal de Santa Catarina (UFSC), Florianópolis, 2008.

DANTAS, Maria Conceição Borges. O perfil dos alunos dos cursos técnicos integrados do IFSP/campus São Paulo: Aproximações críticas sobre os dados preliminares. I CONGRESSO DE EDUCAÇÃO PROFISSIONAL E TECNOLÓGICA DO IFSP - I CONEPT, Sertãozinho, 14 a 18 set. 2015. Anais [...]. Disponível em: http://ocs.ifsp.edu.br/submissao/index.php/conept/i-conept/paper/viewFile/37/117.

Acesso em: 14 jul. 2021.

DAROS, Michelli Aparecida. O Instituto Federal de Educação, Ciência e Tecnologia de São Paulo IFSP, a evasão escolar e a atuação do serviço social: uma experiência em construção (2008-2013). Orientadora: Profa. Dra. Maria Lucia Carvalho da Silva, 2015, 184p. Dissertação (Mestrado) - Pontifícia Universidade Católica de São Paulo (PUC-SP), São Paulo, 2013.

DAROS, Michelli Aparecida. A redução da evasão escolar e o serviço social: experiências no Instituto Federal de Educação, Ciência e Tecnologia de São Paulo. [São Paulo]. O Social em Questão, ano XVIII, n. 33, 2015.

DORE, Rosemary; LÜSCHER, Ana Zuleima. Permanência e evasão na educação técnica de nível médio em Minas Gerais. São Paulo, Caderno de Pesquisa, v. 41, n. 144, p. 772-789, set./dez. 2011.

FIGUEIREDO, Natália Gomes da Silva; SALLES, Denise Medeiros Ribeiro. Educação profissional e evasão escolar em contexto: motivos e reflexões. Ensaio: avaliação das políticas públicas educacionais, Rio de Janeiro, v. 25, n. 95, p. 356-392, abr./jun. 
2017. Disponível em: http://www.scielo.br/pdf/ensaio/2017nahead/1809-4465-ensaioS0104-40362017002500397.pdf. Acesso em: 5 jun. 2019.

HERMOGENES, Natasha Silva Pires. A evasão no curso de licenciatura em física no IFSP na visão dos licenciandos. Orientador: Prof. Jucivagno Francisco Cambuhy Silva. CONGRESSO DE INOVAÇÃO, CIÊNCIA E TECNOLOGIA DO IFSP, Matão, 29 nov. a 2 dez. 2016. Anais [..]. Disponível em: http://mto.ifsp.edu.br/images/CPI/Anais/IC/2328.pdf. Acesso em: 14 jul. 2021.

LEITE, Karina Priscila Aparecida Pinto. Permanência e êxito dos egressos do proeja no campus Sertãozinho do IFSP: um resgate histórico. Orientadora: Profa. Dra. Amanda Ribeiro Vieira. 2020, 178p. Dissertação (Mestrado) - Programa de Pósgraduação em Educação Profissional e Tecnológica em Rede Nacional (ProfEPT), Instituto Federal de Educação Ciência e Tecnologia de São Paulo (IFSP), Sertãozinho, 2020.

LINS, Patrícia Gomes; ARAUJO, Fernando Oliveira de. Fatores Causadores Da Evasão Escolar Na Educação Profissional De Uma Instituição Federal. Revista Científica Multidisciplinar Núcleo do Conhecimento. Ano 06, Ed. 03, Vol. 13, pp. 1947.

Mar. 2021.

Disponível

em:

https://www.nucleodoconhecimento.com.br/educacao/instituicao-federal. Acesso em: 13 jul. 2021.

MATUMOTO, Carolina Ayumi. O estudo de aprendizagem de máquina e sua aplicação no combate à evasão nos cursos do IFSP campus Capivari. Orientador: Prof. Vitor Brandi Junior. 2018, 48 p. Dissertação (Trabalho de Conclusão) - Curso de Tecnologia no Instituto Federal de Educação, Ciência e Tecnologia de São Paulo (IFSP).

Capivari, 2018.

Disponível

em: https://drive.ifsp.edu.br/s/MUozEo1Nd4Jmaio\#pdfviewer. Acesso em: 14 jul. 2021. 
MEC. Ministério da Educação. Portaria Normativa n. 39 de 12 de dezembro de 2007. Brasília, 2007. Disponível em: http://portal.mec.gov.br/arquivos/pdf/portaria_pnaes.pdf. Acesso em: 14 jul. 2021.

MOURA, Marta Alves de Lima. A evasão escolar "mascarada" pelos índices oficiais da secretaria de educação do estado de São Paulo. Orientadora: Profa. Dra. Natália Nassiff Braga. 2017, 64 p. Dissertação (Trabalho de Conclusão de Curso) - Licenciatura no Instituto Federal de Educação, Ciência e Tecnologia de São Paulo (IFSP), Caraguatatuba, $2017 . \quad$ Disponível em: https://drive.ifsp.edu.br/s/lvFzJ0O6eS158Z6\#pdfviewer. Acesso em: 14 jul. 2021.

NORBERTO, Juliana Alvim. A política de assistência estudantil no Instituto Federal de Educação, Ciência e Tecnologia de São Paulo: percepções de alunos sobre acesso e permanência. Orientadora: Profa. Dra. Ângela Maria Martins. 2020, 101p. Dissertação (Mestrado) - Universidade Cidade de São Paulo (Unicid), São Paulo, 2020.

PEREIRA, Daiane Galvão. Proposta de data warehouse para análise de evasão escolar do IFSP - campus de São João da Boa Vista. Orientador: Prof. Ricardo Alexandre Neves, Coorientador Prof. Gustavo Aurélio Prieto. 2014, 121 p. Dissertação (Trabalho de Conclusão) - Curso de Tecnólogo, Instituto Federal de Educação, Ciência e Tecnologia de São Paulo (IFSP). São João da Boa Vista, 2014. Disponível em: https://www.sbv.ifsp.edu.br/component/content/article/72-ensino/trabalhos-epesquisas/173-tcc-sistemas-internet. Acesso em: 14 jul. 2021.

PNP/MEC. Plataforma Nilo Peçanha. Ministério da Educação. PNP - 2020: ano base 2019. Disponível em: http://plataformanilopecanha.mec.gov.br/. Acesso em: 2 fev. 2021.

RIBEIRO, Aline Pires; SANTOS, Thais Cristina. Um estudo sobre os principais fatores de evasão no curso superior de administração no IFSP - Jacareí. Orientadora: Profa. Dra. Renata Plaza Teixeira. 2021, 39 p. Dissertação (Trabalho de 
Conclusão de Curso) - Bacharelado em Administração no Instituto Federal de Educação, Ciência e Tecnologia de São Paulo (IFSP). Jacareí, 2021. Disponível em: https://drive.ifsp.edu.br/s/3GgScjGDi4XdteL\#pdfviewer. Acesso em: 14 jul. 2021.

SANTOS, Danielle de Souza. Democratização do acesso ao ensino médio integrado no IFSP: o contexto da implementação da Lei de reserva de vagas. Orientadora: Profa. Dra. Dirce Djanira Pacheco e Zan. 2018, 232 p. Tese (Doutorado) - Programa de Pós-graduação em Educação da Faculdade de Educação da Universidade Estadual de Campinas (Unicamp), Campinas, 2018.

SANTOS, Fernanda Aparecida Costa; et al. Evasão no IFMG- Campus Piumhi: Estudo de Caso no Curso Técnico Subsequente em Edificações. Revista Científica Multidisciplinar Núcleo do Conhecimento. Ano 05, Ed. 01, Vol. 07, pp. 6578. Jan. 2020.

Disponível

em: https://www.nucleodoconhecimento.com.br/engenharia-civil/evasao-no-ifmg. Acesso em: 13 ago. 2021.

SILVA, Ana Rita Dantas da; HAAS, Célia Maria. Política de assistência estudantil nos três últimos governos: relevância do programa de auxílio permanência. Quaestio, Sorocaba, v. 21, n. 2, p. 503-523, maio/ago. 2019.

SILVA, Adão Rogério Xavier; CARVALHO, Mark Clark Assen de; GONÇALVES, Rafael Marques. Mapeamento e análise das produções científicas que versam sobre as políticas de assistência estudantil no contexto do programa nacional de assistência estudantil. Revista Pedagógica, Chapecó, v. 23, p. 1-30, 2021.

SILVA, Paula Eduarda Soares da. Antirracismo em escolas municipais em Salto: como categorias nativas e analíticas são mobilizadas no ambiente escolar. Orientador: Prof. Dr. Leonardo Borges da Cruz. CONGRESSO DE INOVAÇÃO, CIÊNCIA E TECNOLOGIA DO IFSP, Matão, 29 nov. a 2 dez. 2016. Anais [...]. Disponível em: http://mto.ifsp.edu.br/images/CPI/Anais/IC/2205.pdf. Acesso em: 14 jul. 2021.

RC: 94514

Disponível em: https://www.nucleodoconhecimento.com.br/educacao/instituto-federal 
TCU. Tribunal de Contas da União. Acórdão n. 506. 2013. Auditoria operacional. Fiscalização de orientação centralizada. Rede Federal de Educação Profissional. Disponível em: http://portal2.tcu.gov.br. Acesso em: 14 jul. 2021.

\section{APÊNDICE- REFERÊNCIA DE NOTA DE RODAPÉ}

4. A Plataforma Nilo Peçanha (PNP), iniciada em 2017 pela Secretaria de Educação Profissional e Tecnológica do Ministério da Educação (Setec/MEC), destina-se à coleta, ao tratamento e à publicização de dados oficiais da Rede Federal de Educação Profissional, Científica e Tecnológica.

5. Programa Nacional de Integração da Educação Profissional com a Educação Básica na Modalidade de Educação de Jovens e Adultos (Proeja), instituído pelo Decreto Federal n. 5.840, de 13 de julho de 2006.

6. A Formação Inicial e Continuada (FIC) foi instituída pelo Decreto federal n. 8.268, de 18 de junho de 2014.

7. A verticalização está prevista no Art. 6o, inciso III, da Lei n. 11.892/2008, como finalidade e características dos IFs para "promover a integração e verticalização da educação básica à educação profissional e educação superior, otimizando a infraestrutura, os quadros de pessoal e os recursos de gestão" (BRASIL, 2008).

8. Russell W. Rumberger é Professor Emérito, Ph.D., Universidade de Stanford no Departamento de Educação. [...] o Professor Rumberger publicou amplamente em diversas áreas da educação: educação e trabalho; a escolaridade de alunos desfavorecidos, especialmente alunos que abandonaram a escola e alunos de minorias linguísticas; eficácia escolar; e política de educação. Ele tem conduzido pesquisas sobre evasão escolar nos últimos 30 anos e escreveu mais de 40 artigos de pesquisa e ensaios sobre o assunto. Fonte: UC Santa Barbara, The Gevirtz School. Disponível em: https://education.ucsb.edu/russell-rumberger. Acesso em: 17 ago. 2021.

RC: 94514

Disponível em: https://www.nucleodoconhecimento.com.br/educacao/instituto-federal 
9. Cislaghi (2008) aborda os modelos apresentados por autores como Spady (1970; 1971); Bean (1980); Bean e Metzner (1985); Tinto (1975; 1993; 1997); Pascarella (1980); Astin (1985); MacKinnon-Staney (1991); Cabrera; Nora; e Castañeda (1992); Nora; Barlow; e Crisp (2005); e Brandon; Hirschy; e McClenton (2004).

10. RIBEIRO, Aline Pires e SANTOS, Thais Cristina, são discentes do Bacharelado em Administração no campus Jacareí, que orientadas pela Profa. Dra. Renata Plaza Teixeira, realizaram em conjunto a pesquisa "Um estudo sobre os principais fatores de evasão no curso superior de administração no IFSP - Jacareí.", resultando este presente estudo em treze trabalhos e quatorze autores.

11. IFSP-Brt - Instituto Federal de São Paulo, campus Barretos.

12. Técnicos em Assuntos Educacionais (TAEs).

13. A ferramenta WEKA, desenvolvida em Java, é uma coleção de algoritmos de Aprendizagem de Máquina para mineração de dados. Foi criada na Universidade de Waikato, na Nova Zelândia, e é um software open source (MATUMOTO, 2018).

Enviado: Agosto, 2021.

Aprovado: Agosto, 2021.

RC: 94514

Disponível em: https://www.nucleodoconhecimento.com.br/educacao/instituto-federal 